\title{
Intracerebral haemorrhage after thrombolytic therapy for acute myocardial infarction
}

\author{
R.S. More and R. Vincent \\ Department of Cardiology, Royal Sussex County Hospital, Brighton, UK
}

\begin{abstract}
Summary: Seven cases of intracerebral haemorrhage were identified following the use of thrombolytic therapy in a total of $\mathbf{7 1 0}$ patients with acute myocardial infarction. Each case was reviewed in detail with particular attention to the presenting symptoms. A confusional state was the commonest initial feature. Increased age and male sex were associated with increased risk of cerebral bleed. The possible role of intravenous heparin in increasing risk and the management of affected cases is discussed. Early recognition and action is emphasized.
\end{abstract}

\section{Introduction}

The widespread acceptance of thrombolytic therapy for acute myocardial infarction has focused increasing attention on the potential problems associated with its use, in particular the risk of intracerebral haemorrhage. Although the use of thrombolytic agents results in a reduction in nonhaemorrhagic strokes complicating myocardial infarction, an increased risk of cerebral haemorrhage occurs that is associated with death or considerable morbidity.

The overall incidence of intracerebral haemorrhage from the use of thrombolytic agents is less than $1 \% \cdot{ }^{1-3}$ In ISIS-2, a risk of $0.1 \%$ was noted in those given streptokinase alone, whilst the TIMI group mentioned a rate of $0.5 \%$ with $100 \mathrm{mg}$ of recombinant tissue plasminogen activator (rt-PA). ${ }^{4}$ In ISIS-3 a stroke rate of $0.3 \%$ with streptokinase, $0.7 \%$ with rt-PA and $0.6 \%$ with anistreplase was observed. The risk appears to correlate with thrombolytic efficacy, ${ }^{5,6}$ increasing the dose of rt-PA to $150 \mathrm{mg}$ is associated with a marked increase in risk of cerebral bleed. ${ }^{4}$

Early recognition of cerebral haemorrhage may allow time for reversal of thrombolysis and thus limit subsequent deterioration. We therefore elected to review our experience in the Royal Sussex County Hospital of individuals with intracerebral haemorrhage following the use of thrombolytic agents to assess whether any early clinical characteristics could predict subsequent deterioration. Seven cases were identified for analysis.

Correspondence: R.S. More, M.R.C.P., Department of Cardiology, Glenfield General Hospital, Groby Road, Leicester LE3 9QP, UK.

Accepted: 6 March 1992

\section{Case reports}

Case 1

A 72 year old man with a past history of transien ischaemic attacks and exertional angina was admi ted with an extensive inferior and anterolater速 myocardial infarction. He had a regular pulse of $70 /$ minute and systolic blood pressure (BP) $100 \mathrm{mmHg}$. Anistreplase (30 units) was given 1.5 hours after the onset of symptoms and a few minutes later he had an episode of ventricular fibrillation terminated by DC shock. He was subsequently commenced on intravenous (i.v.) heparin. On the following day he was found on the floor, fully conscious, having apparently banged his head. Subsequently he rapidly became unconscious. A computed tomographic (CT) scan revealed extensive intracerebral haemorrhage. He died 40 hours later.

\section{Case 2}

A 78 year old man with a preceding history of $D$ exertional angina was admitted with a 3 hour history of retrosternal chest pain. On admission he N was noted to be in atrial fibrillation with a rate of 120/minute and BP $190 / 120 \mathrm{mmHg}$. The electro- 0 cardiogram (ECG) showed changes of an acute $\underset{\omega}{ }$ inferior myocardial infarction. He was given anistreplase 30 units (BP had decreased to 180/110). Six hours later he became confused and neuro- $\mathbb{D}$ logical examination revealed bilateral extensor $\stackrel{\oplus}{?}$ plantars. He subsequently developed right-sided $T$ flaccid weakness and had frank haematuria. He had not received any i.v. heparin. Tranexamic acid (1 $\mathrm{g}$ i.v.) was given but his condition deteriorated 
further and he died 15 hours later. Permission for a postmortem was refused by the family.

\section{Case 3}

A 71 year old hypertensive male was admitted with an acute inferior myocardial infarction. On arrival he was in atrial fibrillation 130 /minute with BP $140 / 80 \mathrm{mmHg}$. Seven hours after being given 1.5 million units of streptokinase and one hour after administration of 10,000 units i.v. heparin he complained of right-sided hemianaesthesia. Thereafter his condition deteriorated quickly; he acquired right hemianopia and hemiparesis, and died several hours later. A postmortem revealed haemorrhage into the left cerebral hemisphere.

\section{Case 4}

A 58 year old man who had a myocardial infarction 22 years previously was admitted with an acute anterior infarct. Thirty units of anistreplase were administered within 3 hours of the onset of pain. He was in sinus rhythm with a BP $110 / 70 \mathrm{mmHg}$. Seven hours later and one hour after being given 10,000 units of i.v. heparin, he became confused and complained of a generalized headache. At that time it was noted that his lower abdomen had a blue and mottled appearance. One hour later he complained of hypoaesthesia in his legs and became paraplegic. At that stage it was felt that these problems were secondary to emboli to his cerebrum and aortic bifurcation. Anticoagulation with i.v. heparin was continued. However, he continued to deteriorate and 4 hours later he was deeply unconscious, with a dilated and fixed left pupil, and a pulse of 35/minute and BP 210/ $110 \mathrm{mmHg}$. Intravenous protamine sulphate, mannitol, fresh frozen plasma (FFP) and tranexamic acid were given to no avail. Postmortem findings were a right intracerebral hemisphere haematoma, left ventricular mural thrombus, and thrombus occluding the infrarenal portion of the abdominal aorta.

\section{Case 5}

A 75 year old man with a previous myocardial infarction was admitted with an acute anterior infarction. He had a regular pulse of $70 /$ minute with BP $170 / 90 \mathrm{mmHg}$. Streptokinase $(1.5$ million units) was administered 3.5 hours after the onset of pain. Several minutes later he felt 'odd' and became very sweaty. It was felt these symptoms may have been due to an allergy to streptokinase and he was given i.v. chlorpheniramine. Ten hours later he became agitated and confused, and complained of frontal headaches. Examination revealed nuchal rigidity and a subarachnoid haemorrhage was suspected. He had received 10,000 units i.v. heparin one hour previously. He was given i.v. tranexamic acid, FFP and protamine sulphate. A CT scan at that time revealed bilateral temporal lobe haemorrhage. He remained drowsy and unwell for several days. By the time of discharge he was fully mobile but left with considerable impairment of shortterm memory.

\section{Case 6}

A 56 year old man with a past history of hypertension, stroke and non- $Q$ wave myocardial infarction was admitted with 4 hour history of central chest pain radiating to the left arm. An ECG showed T wave inversion in the lateral leads and his chest $\mathrm{X}$-ray showed cardiomegaly and pulmonary oedema. He was commenced on diuretics and nitrates. The following day he had recurrent pain and a repeat ECG showed atrial fibrillation and ST segment elevation in leads 1, AVL and V4-V6. Anistreplase 30 units was administered 2 hours after the onset of pain. His general condition deteriorated and he became confused and increasingly short of breath. He was given two units of FFP. Soon afterwards he was noted to have an expressive dysphasia and more marked right-sided weakness. A CT scan revealed haemorrhage into a pre-existing infarction in the left middle cerebral artery territory. By the time of discharge some improvement in his disabilities was noted and he was able to mobilize himself without help.

\section{Case 7}

A 64 year old man was admitted after a prolonged episode of epigastic pain secondary to an inferior myocardial infarction. Over the preceding 2 months he had experienced several shorter-lived episodes of similar pain. He was given anistreplase within 5 hours of the onset of pain. Intravenous heparin was commenced in addition to $10 \mathrm{mg}$ i.v. atenolol. Twenty-four hours after admission he complained of left-sided weakness. He was given i.v. tranexamic acid, FFP and protamine sulphate. Despite these measures he deteriorated further with recurrent vomiting and increasing drowsiness and died 7 hours later. Postmortem examination revealed extensive haemorrhage into the right lateral ventricle.

\section{Discussion}

Over the period of review, thrombolytic therapy had been administered to 710 patients, giving an intracerebral haemorrhage rate of $1.0 \%$. This is similar to the rate reported by O'Connor et al. ${ }^{7}$ and 
De Jaegere's group ${ }^{8}$ but higher than that mentioned by others. ${ }^{1-4}$

Several factors have been reported to be associated with increased risk of intracranial haemorrhage. A history of hypertension has been mentioned, although this did not appear to be applicable to our patients. Like other groups we found increased age to a significant factor for increased risk; four of our seven patients were over the age of 70 years. Individuals on long-term anticoagulants constitute a particularly high-risk group ${ }^{8}$ but this was not relevant to our patients, since our policy has been to avoid thrombolytic therapy in such individuals. The site of the myocardial infarction was unhelpful in predicting those with increased risk of intracranial haemorrhage; three had inferior myocardial infarction, three anterior infarction and one had both anterior and inferior changes. It is of interest that all our affected cases were men, despite the fact that $168(24 \%)$ of the total 710 individuals given thrombolytic therapy were females. O'Connor's group noted that $70 \%$ of their patients with intracerebral haemorrhage were men.

A factor likely to be of relevance in our affected patients was the use of intravenous heparin after thrombolysis which four of the five patients who died had received. During the period of this review we used an initial regimen of 40,000 units/24 hours as 6 hourly boluses, commencing 6 hours after streptokinase or anistreplase had been given. This particular heparin dosage regimen was one that we and others ${ }^{9}$ had developed and used in the prethrombolytic era. Intermittent bolus dosages had the benefit of not requiring use of a syringe pump and allowing earlier mobilization of patients. In the absence of data to indicate any alternative strategy, this heparin regimen was continued after the introduction of thrombolytic therapy. Although the activated partial thromboplastin time (APPT) was not checked routinely it was monitored in any individual who developed bleeding complications. Since the period of this review and in the light of published data, we have changed our heparin regimen to 12,500 units subcutaneously twice a day, commencing 12 hours post-thrombolysis. In fact, the precise role of heparin following thrombolysis is not yet resolved. ${ }^{10}$ Higher coronary artery patency rates are achieved at $48-72$ hours if i.v. heparin is commenced immediately after rt-PA infusion has been completed. " But the GISSI-2 study showed that heparin $(12,500$ unit subcutaneously twice a day starting 12 hours after either streptokinase or rt-PA) made no overall difference to the figures for combined mortality or severe left ventricular dysfunction. ${ }^{12}$ Furthermore, the ISIS-3 study revealed similar findings and a higher intracerebral haemorrhage rate $\left(0.6 \%\right.$ com- $\frac{\varrho}{3}$ pared with $0.4 \%$ ) in those patients given i.v. $\stackrel{\mathbb{Q}}{\stackrel{2}{2}}$ heparin.

The clinical presentation of intracerebral haemorrhage can be very variable. De Bono $\stackrel{0}{\rightarrow}$ categorized such patients into two groups. ${ }^{5}$ Firstly, those who presented with abrupt onset of symp- $\frac{\bar{\sigma}}{\bar{D}}$ toms such as headache, vomiting and development $\frac{\omega}{\sigma}$ of focal neurological deficits. The second group, $\stackrel{\varnothing}{\varrho}$ however, presented with more insidious symptoms, क usually progressive drowsiness. O'Connor's group $\vec{\circ}$ reported profound nausea and vomiting to be the commonest initial complaint. However, in our $\vec{\omega}$ patients, confusion (four of the seven cases) was the commonest initial feature. In addition, two had headaches and three focal neurological deficits. In all, except the case with head injury, presentation was several hours after administration of thrombolytic therapy. Profound nausea and vomiting was a prominent feature in only one. Intracranial haemorrhage was associated with considerable morbidity and a high mortality rate. Five individuals died and the other two were left with disabling deficits. Similar high mortality rates have been reported by others. ${ }^{8}$

Effective management could only occur if there were early recognition of the problem. The pose sibility of an intracerebral bleed should be considered seriously in any individual given throme bolytic therapy who subsequently develops confusion, headaches or profound nausea and vomiting. Although treatment in our patients did not appear to influence outcome, this was probably because of delay in initiating such treatment; more than 2 hours in three of the five treated individuals. One of the two patients who received prompt treatment survived. Any effective therapy would have to involve both reversal of thrombolysis and replenishment of depleted coagulation factors. The latter can be achieved by infusing fresh frozen plasma. Antifibrinolytic agents, which cause reversal of plasminogen activation and inhibition of plasmin activity, include aminocaproic acid, aprotinin and tranexamic acid. We used tranexamic acid $(10 \mathrm{mg} / \mathrm{kg}$ with the dose repeated later if required), which acts by inhibiting plasminogen activation and plasmin action by competing with lysine binding sites. ${ }^{13}$

In conclusion, early recognition of intracerebral haemorrhage following thrombolysis is important and may allow time for action to limit the severe disabilities or death that often results. The presently available measures, tranexamic acid and fresh frozen plasma, appear to have partial benefit if commenced promptly. Alternative, more effective, therapies need to be developed. 


\section{References}

1. AIMS Trial Study Group. Effect of intravenous APSAC on mortality after acute myocardial infarction: preliminary report of a placebo-controlled clinical trial. Lancet 1988, i: $545-549$.

2. ISIS-2 Collaborative Group. Randomised trial of intravenous streptokinase, oral aspirin, both or neither among 17,187 cases of suspected acute myocardial infarction. ISIS-2 Lancet 1988, ii: $349-360$.

3. Wilcox, R.G., vonder Lippe, G., Olsson, C.G. et al. Trial of Tissue Plasminogen Activator for mortality reduction in acute myocardial infarction: Anglo-Scandinavian study of early thrombolysis (ASSET). Lancet 1988 , ii: 525-530.

4. The TIMI Study Group. Comparison of invasive and conservative strategies after treatment with intravenous tissue plasminogen activator in acute myocardial infarction. Results of the thrombolysis in myocardial infarction (TIMI) phase II trial. $N$ Engl J Med 1989, 320: 618-627.

5. de Bono, D. Problems in thrombolysis. In: Julian, D. Verstraete, M., Collen, D. et al. (eds). Thrombolysis in Cardiovascular Disease. Marcel Dekker, New York, 1989, pp. 279-292.

6. The TIMI Study Group. Thrombolysis in myocardial infarction (TIMI) trial - Phase 1; haemorrhagic manifestations and changes in plasma fibrinogen and the fibrinolytic system in patients treated with recombinant tissue plasminogen activator and streptokinase. J Am Coll Cardiol 1988, ii: 1-11.
7. O'Connor, C.M., Aldrich, H., Massey, E.W. et al. Intracranial haemorrhage after thrombolytic therapy for acute myocardial infarction: clinical characteristics and in-hospital outcome (abstract). J Am Coll Cardiol 1990, 15(2): 213A.

8. De Jaegere, P., Balk, A. \& Simoons, M. Intracranial haemorrhage and thrombolytic therapy (abstract). Eur Heart J 1990, 11: 147 .

9. Oram, S. Clinical Heart Disease. William Heinmann Medical Books Ltd, London, 1981, pp. 451-452.

10. Wilcox, R.G. Coronary thrombolysis: round two and beyond. Br Heart J 1991, 65: 175-176.

11. Gruppo Italiano per lo Studio della Supravivenza nell'Infarte Micardico, GISSI-2: A factorial randomised trial of alteplase versus streptokinase and heparin versus no heparin among 12,490 patients with acute myocardial infarction. Lancet 1990, ii: $65-72$.

12. Bleich, S.D., Nichols, T., Schumacher, R. et al. The role of heparin following coronary thrombolysis with tissue plasminogen activator (t-PA). Circulation 1989, 80 (Suppl. II:II113).

13. Prentice, C.R.M. Basis of antifibrinolytic therapy. J Clin Path (33. Suppl. (R. Coll. Path)), 1980, 14: 35-40. 